\title{
Marriage to First Birth Interval; A Cross-Sectional Study in Tehran (Iran)
}

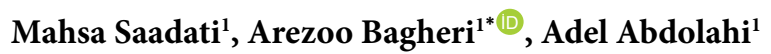

\begin{abstract}
Objectives: One of the features of fertility below replacement level is the increase of the first birth interval which has occurred at the same time with the rise of women's marriage age in recent years in Iran. Since determination of factors affecting delay in childbearing can provide convenient approaches to prevent fertility decline, the aim of this study was to evaluate socio-economic factors influencing the first birth interval in married women in Tehran province, Iran.

Materials and Methods: In a cross-sectional study, 610 married women aged 15 to 49 years were selected by the stratified random sampling and a structured questionnaire was used in 2017. Women's first birth intervals were compared in terms of some demographic and socio-economic factors by Kaplan-Meier (KM) estimates and Log-Rank test for univariate and Cox model for multivariate survival analysis using SPSS version 22.0.

Results: The mean of women's first birth intervals was 3.181 \pm 0.101 years. Women's educational level and social insecurity had significant effects on the first birth interval $(P$ value $<0.05)$. By increasing educational level and social insecurity, the first birth interval also increased. Women with "secondary and high school" and "MS and $\mathrm{PhD}$ " educational levels had the shortest and longest first birth intervals, respectively.

Conclusions: According to results, unless governments provide the condition of social security, reducing the interval between marriage age and childbearing will not be attained.

Keywords: First birth intervals, Kaplan-Meier estimates, Cox model, Tehran, Iran
\end{abstract}

\section{Introduction}

Fertility is an important component of population dynamics which plays a major role in changing the size and the structure of a given population (1). Fertility analysis is a vital issue for policymakers to conclude guidance for population control and also for the evaluation of family planning programs (2). In less than a decade, Iran has experienced fertility below the replacement level, and currently, it has the lowest fertility rate in the Middle East. Studies on the fertility rate indicated that the total fertility rate (TFR) has reduced from 7 births per woman in 1979 to 1.9 in 2006 and 1.8 in 2011. This decline is observed not only in urban but also in rural areas (3-5). Thus, it is important to study the factors affecting the low fertility in the country.

In studies which investigate fertility reduction, usually, two influential dimensions of fertility including tempo (childbearing time) and quantum (number of children) are considered. When the aim of the study is to investigate delayed fertility, tempo is a suitable index. If the first child was born at young ages of mother and a short interval after her marriage, achieving next pregnancies may occur faster. On the other hand, by increasing mother's age and the interval between her marriage and her first birth, in addition to a reduction in TFR, completed dimension of her family is also reduced (6). Thus, in the society with a low fertility rate, a delayed childbearing may cause a low fertility pattern. Studying the first birth interval, among many indices that affect the identification of the fertility pattern, has many advantages because in the postmarriage, the period of the first fertility is less forgotten and almost all women remember their first pregnancy information. Additionally, in this period, the delay in the menstrual cycle that occurs after each fertilization is not observed. The other fertility times are heavily affected by irregular changes during this period $(7,8)$.

According to the importance of the delayed childbearing, many researchers studied this phenomenon recently in Iran. McDonald et al used the data of Demographic Health Research (DHS) in 2010 to calculate the parity progression ratio in Iran. According to this study, in 2010, the women's interval between marriage and their first birth increased to 3.5 years (9). This interval was 2.7 years in the study of Abbasi-Shavazi and Razeghi Nasrabad, which was conducted, based on the DHS data in 2000 (6). Saadati and Bagheri also studied the duration of the first birth and its determinants in Semnan province using the parametric survival model. Their results indicated that the average interval between marriage and the first birth was 2.76 years and $90 \%$ of women had given birth to their first 
child 4 years after their marriage (10).

Expansion and universalization of education, urbanization and increased participation of women are important achievements of modernization which contribute greatly to the change of attitudes and fertility behaviors. On the other hand, the revolution in reproduction and the access to the contraceptives, which is also one of the achievements of technological advances, should be taken into account in the evaluation of factors affecting the delay in childbearing. Increasing educational levels of women (6), providing a balance between an individual and family goals (9), an increase in the education level of children and a reduction in child mortality, (11) are influential factors affecting the first childbearing. Some other studies also concluded that employed mothers gain less work experience and income than men or childless women. On the other hand, women who experience their maternity at older ages are able to achieve high levels of human capital, including stable jobs with higher status and wage $(12,13)$. Therefore, women who want to achieve a career success delay their maternity.

In recent years, there has been an increasing amount of literature on different dimensions of insecurity. Feeling insecure depends on the mental interpretation of people about the condition of society. The high percent of the economic and social disorder can lead to feeling insecure. In such situation, it is difficult to predict progressive conditions. Therefore, when uncertainty is high, people prefer to avoid decision-making for longterm commitments like childbearing and its consequences (14-16). In this regard, several studies emphasized new social risks, which are the results of socio-economic changes. What we know about insecurity is largely based on empirical studies that investigate how insecurity can lead to decrease in childbearing. However, far too little attention has been paid to the effect of insecurity on childbearing attitude in families in Iran.

Given the importance of studying the first birth interval, the aim of this paper was to investigate the effect of important dimensions of insecurity including economic, social, and psychological, and some important demographic and socio-economic factors on first birth interval. The data were obtained from a survey entitled "the effect of socio-economic dimensions of rationality on childbearing behavior in Tehran" (17) including 610 Iranian women and were analyzed based on Kaplan-Meier (KM) estimates and Log-Rank test for univariate and Cox proportional hazards $(\mathrm{PH})$ model for multivariate survival analysis.

\section{Materials and Methods}

In a cross-sectional study, a structured questionnaire was used to collect the data from 610 Iranian married women aged 15-49 years. They were selected by multistage stratified random sampling from different regions of Tehran province. The structured questionnaire collected demographic information, fertility history and childbearing attitudinal factors including economic insecurity, plan-based behavior, parental identity, positive and negative values, social insecurity, postmaterialism, conflict between child and parental duty, psychological insecurity, male breadwinner, individualism, perception of the child, and increasing child cost in 2017 (17). The validity of the questionnaire was confirmed by 10 demographers and sociologists, and its reliability was at least 0.771 using Cronbach $\alpha$. Since there were not any interventions or treatment in this study and the aim of the study was explained to the respondents before interviewing, there is no requirement for ethics code.

In this study, KM estimates and log-rank test were used as nonparametric survival tools for univariate analysis to describe women's first birth interval according to covariates of their age at marriage, women's and their husbands educational level, women's and their husbands' activity, and economic, social and psychological insecurity.

To determine effective factors, Cox $\mathrm{PH}$ model was applied for multivariate analysis (18). This model contains two components including baseline hazard $\left(\mathrm{h}_{0}(\mathrm{t})\right)$ and predictor statement $\left(\exp \left(b_{1} x_{1}+\ldots .+b_{n} x_{n}\right)\right)$. Due to the simplicity of this model, it is applied in many demographic and medical studies including marriage age and birth interval $(19,20)$.

Cox model is generally described as Equation (1):

$h(t)=h_{0}(t) \exp \left(b_{1} x_{1}+\ldots .+b_{n} x_{n}\right)(1)$

$h_{0}(t)$ is the subject's hazard considering no covariates $\left(x_{1}=x_{2}=\ldots=x_{n}=0\right)$, and $\left(b_{1}=b_{2}=\ldots=b_{n}\right)$ shows the effect of each covariate. Fitting model without determining $h_{0}(t)$, is one of the characteristics of Cox model that makes it a simple model. Proportionality of hazards over time is the important assumption to obtain valid results in Cox model. It means that the estimated hazard ratio for two subjects with specified covariate will be fixed over time. When this important hypothesis is not confirmed, the model is not effective and its results are not reliable. Therefore, in this study, $\mathrm{PH}$ assumptions were checked by time-dependent Cox model, which confirmed this hypothesis for all covariates.

\section{Results}

The mean age of women, age at first marriage and first birth interval were $35.38 \pm 7.91,22.59 \pm 4.39$, and $3.27 \pm 2.63$ years, respectively. The mean score of economic, social and psychological insecurity factors were $3.52 \pm 1.20$, $4.19 \pm 0.64$, and $2.96 \pm 0.89$, respectively. Table 1 shows the frequency and percentage of demographic characteristics. Most of the women married at age 20 to 24 (43.1\%), had a diploma (41.3\%) and were unemployed (67.9\%). 43.3\% of the women and $46.4 \%$ of their husbands had university education. Only $4.3 \%$ of the women's husbands were unemployed.

KM survival estimates are computed for women's first birth intervals and their survival curve is shown in Figure 
Table 1. Frequency Distribution of Women's Demographic Characteristics

\begin{tabular}{|c|c|c|c|}
\hline Variable & Categories & No. & Percent \\
\hline \multirow{5}{*}{$\begin{array}{l}\text { Age at first } \\
\text { marriage }\end{array}$} & $\leq 19$ & 154 & 25.2 \\
\hline & $20-24$ & 263 & 43.1 \\
\hline & $25-29$ & 138 & 22.6 \\
\hline & $30-34$ & 46 & 7.5 \\
\hline & $\geq 35$ & 4 & .7 \\
\hline \multirow{5}{*}{$\begin{array}{l}\text { Woman } \\
\text { educational level }\end{array}$} & Illiterate & 33 & 5.4 \\
\hline & Secondary \& high school & 44 & 7.2 \\
\hline & Diploma & 252 & 41.3 \\
\hline & $\mathrm{BC}$ & 209 & 34.3 \\
\hline & MS \& PhD & 61 & 10.0 \\
\hline \multirow{5}{*}{$\begin{array}{l}\text { Husband } \\
\text { educational level }\end{array}$} & Illiterate & 33 & 5.4 \\
\hline & Secondary \& high school & 78 & 12.8 \\
\hline & Diploma & 203 & 33.3 \\
\hline & $\mathrm{BC}$ & 204 & 33.4 \\
\hline & MS \& PhD & 79 & 13.0 \\
\hline \multirow{2}{*}{ Woman activity } & Employed & 195 & 32.0 \\
\hline & Unemployed & 414 & 67.9 \\
\hline \multirow{2}{*}{ Husband activity } & Employed & 26 & 4.3 \\
\hline & Unemployed & 573 & 93.9 \\
\hline Total & & 610 & 100.0 \\
\hline
\end{tabular}

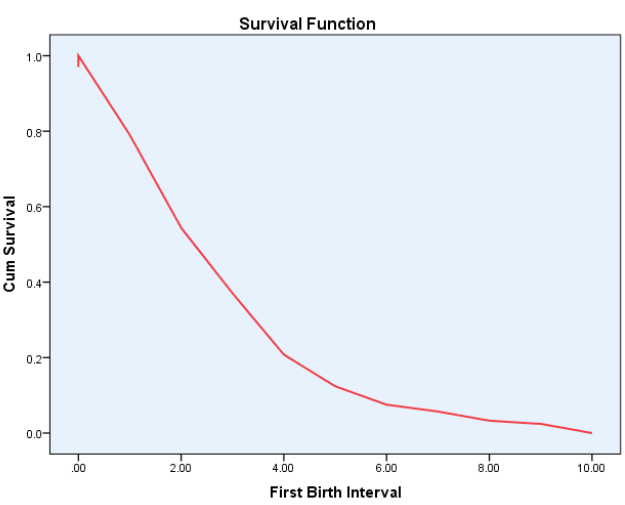

Figure 1. Kaplan-Meier Survival Curve of First Birth Interval.

1. As this figure displays, most of the women's first birth interval (about 87\%) were less than 5 years.

KM means and standard errors and $P$ value of Log-Rank test for women's first birth interval according to selected covariates are given in Table 2. These indicators help to understand the average and significant differences of this variable among various categories of covariates. As results of this table shows, $\mathrm{KM}$ mean of the first birth interval was

Table 2. Kaplan-Meier Estimates of First Birth Interval by Covariates

\begin{tabular}{|c|c|c|c|c|}
\hline \multirow{2}{*}{ Variable } & \multirow{2}{*}{ Categories } & \multicolumn{2}{|c|}{ Mean } & \multirow{2}{*}{ Log-Rank Test ( $P$ Value) } \\
\hline & & Estimate & SE & \\
\hline \multirow{5}{*}{ Age at first marriage } & $\leq 19$ & 3.066 & 0.192 & \multirow{5}{*}{0.345} \\
\hline & $20-24$ & 3.272 & 0.161 & \\
\hline & $25-29$ & 3.343 & 0.206 & \\
\hline & $30-34$ & 2.964 & 0.369 & \\
\hline & $\geq 35$ & 1.750 & 0.750 & \\
\hline \multirow{5}{*}{ Woman's educational level } & Illiterate & 2.800 & 0.402 & \multirow{5}{*}{$<0.000^{* *}$} \\
\hline & Secondary \& high school & 2.262 & 0.224 & \\
\hline & Diploma & 2.976 & 0.144 & \\
\hline & $\mathrm{BC}$ & 3.705 & 0.199 & \\
\hline & $\mathrm{MS} \& \mathrm{PhD}$ & 3.595 & 0.386 & \\
\hline \multirow{5}{*}{ Husband's educational level } & Illiterate & 2.655 & 0.307 & \multirow{5}{*}{$0.002 * *$} \\
\hline & Secondary \& high school & 2.574 & 0.247 & \\
\hline & Diploma & 2.982 & 0.157 & \\
\hline & $\mathrm{BC}$ & 3.599 & 0.191 & \\
\hline & MS \& PhD & 3.672 & 0.346 & \\
\hline \multirow{2}{*}{ Woman's activity } & Employed & 3.597 & 0.211 & \multirow{2}{*}{$0.011^{*}$} \\
\hline & Unemployed & 3.010 & 0.113 & \\
\hline \multirow{2}{*}{ Husband's activity } & Employed & 2.316 & 0.351 & \multirow{2}{*}{$0.042^{*}$} \\
\hline & Unemployed & 3.219 & 0.105 & \\
\hline \multirow{3}{*}{ Economic insecurity } & Low & 3.437 & 0.277 & \multirow{3}{*}{0.455} \\
\hline & Middle & 3.040 & 0.242 & \\
\hline & High & 3.241 & 0.135 & \\
\hline \multirow{3}{*}{ Social insecurity } & Low & 4.000 & 0.000 & \multirow{3}{*}{0.122} \\
\hline & Middle & 2.435 & 0.294 & \\
\hline & High & 3.239 & 0.107 & \\
\hline \multirow{3}{*}{ Psychological insecurity } & Low & 3.250 & 0.224 & \multirow{3}{*}{0.747} \\
\hline & Middle & 3.289 & 0.149 & \\
\hline & High & 3.050 & 0.168 & \\
\hline Total & & 3.181 & 0.101 & \\
\hline
\end{tabular}

Abbreviation: SE, standard error.

* Significant at 0.05 level, ** Significant at 0.01 level. 
$3.18 \pm 0.101$, excluding age at first marriage and economic, social, and psychological insecurity, the other covariates had significant effect on the first birth interval $(P<0.05)$.

Figure 2 displays the survival curves of the women's first birth interval, by significant covariates.

The pattern of the survival curves for the educational levels (Figures 2A and 2B) showed that by increasing women's and their husbands' educational level, the first birth interval also increased. These variations were also proved by significant Log-Rank test $(P<0.01)$. University educated women and their husbands had the longest first birth interval compared to the other educational levels. Employed women had a greater mean of the first birth interval (3.597) than unemployed ones (3.010), women with unemployed husbands had longer first birth interval (3.22) than employed ones (2.32) (Table 2). These differences were significant at 0.05 level. Figures $2 \mathrm{C}$ and $2 \mathrm{D}$ confirmed these patterns. These results are in the opposite direction of each other.

To investigate the effects of all covariates on first birth interval simultaneously, Cox model was used. It should be noted that $\mathrm{PH}$ hypothesis for all covariates was checked and confirmed by time-dependent Cox model. Shorter and longer birth intervals were achieved when hazard ratios were above and below 1, respectively. The hazard ratio greater than 1 increases the hazard rate of first birth interval (lead to birth interval). On the other hand, the hazard ratio less than 1 decrease the hazard rate of duration of first birth (lead to birth interval). The statistical significance of the Cox coefficient model indicates whether these changes in expected duration will be statistically significant or not.

Table 3 presents the results of Cox model. As the table shows, only women's educational level and social insecurity had significant effects on the first birth interval $(P<0.05)$.

The HR of the shorter first birth interval in women with secondary and high school educational levels was almost 2 times higher compared to women with MS and $\mathrm{PhD}$ educational levels. In other words, women with $\mathrm{MS}$ and $\mathrm{PhD}$ educational levels had longer duration of childlessness compared to those with secondary and high school education. The same results can be calculated for women with a diploma. By increasing women's social insecurity, the HR of shorter first birth interval decreased $(\mathrm{HR}=0.825)$. It means that women's social insecurity leads to delay in their childbearing.

\section{Discussion}

The study of the dynamics of timing and spacing of births is important for several reasons, including an understanding of completed family size as well as maternal and child mortality (21). Due to the decrease in TFR below replacement level recently in Iran, many studies investigated the effect of factors on the birth interval $(3,5,6,11)$. To the best of our knowledge, there were not any
(A)

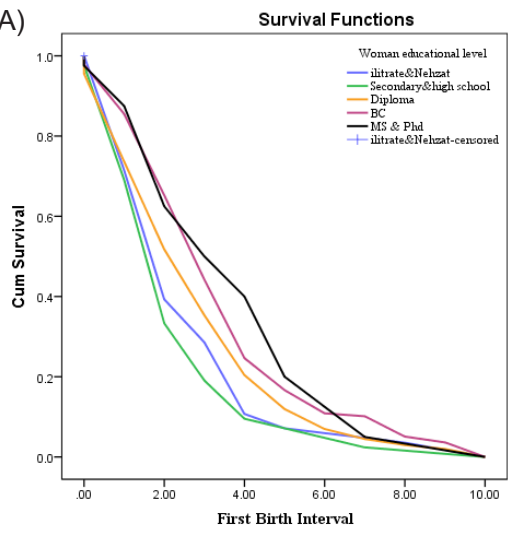

(C)

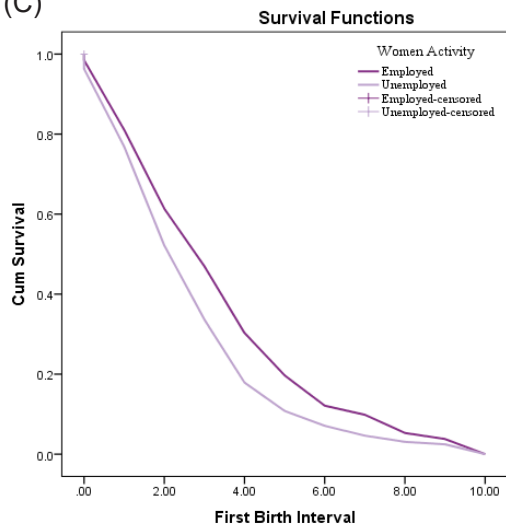

(B)

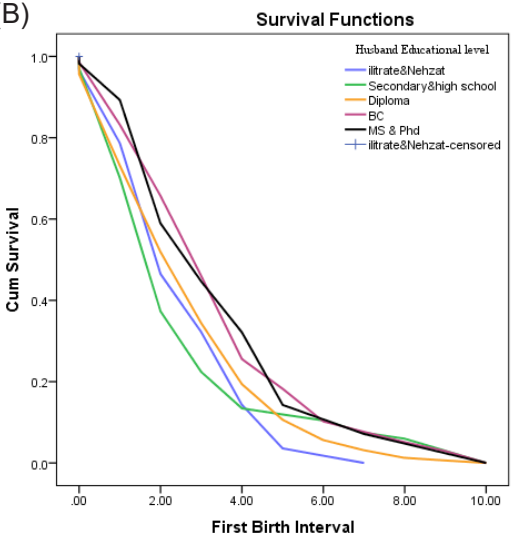

(D)

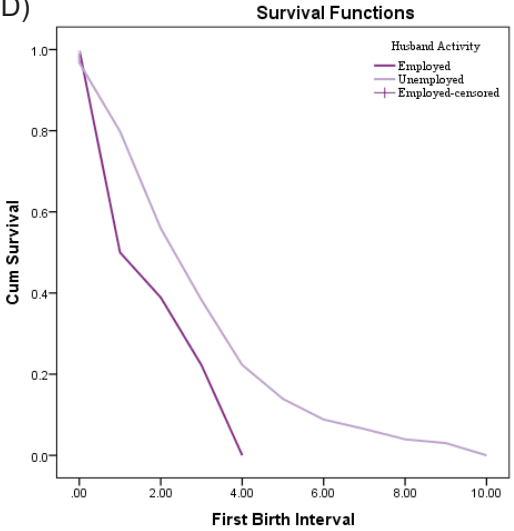

Figure 2. Kaplan-Meier Survival Curves of Women's First Birth Interval by Significant Covariates. 
Table 3. Cox Model for First Birth Interval

\begin{tabular}{|c|c|c|c|c|c|}
\hline Variable & & $\beta$ & SE & HR & $P$ Value \\
\hline Age at first marriage & & 0.010 & 0.014 & 1.010 & 0.507 \\
\hline \multirow{5}{*}{ Woman's educational level } & Illiterate & 0.479 & 0.266 & 1.614 & 0.071 \\
\hline & Secondary \&high school & 0.747 & 0.242 & 2.111 & $0.002 * *$ \\
\hline & Diploma & 0.490 & 0.198 & 1.632 & $0.014 *$ \\
\hline & $B C$ & 0.200 & 0.204 & 1.221 & 0.328 \\
\hline & MS \& PhD (ref) & & & & \\
\hline \multirow{5}{*}{ Husband's educational level } & Illiterate & 0.470 & 0.339 & 1.599 & 0.165 \\
\hline & Secondary \&high school & 0.365 & 0.275 & 1.440 & 0.184 \\
\hline & Diploma & 0.270 & 0.237 & 1.311 & 0.253 \\
\hline & $\mathrm{BC}$ & 0.135 & 0.226 & 1.144 & 0.551 \\
\hline & MS \& PhD (ref) & & & & \\
\hline \multirow{2}{*}{ Woman's activity } & Employed & -0.129 & 0.130 & .879 & 0.318 \\
\hline & Unemployed (ref) & & & & \\
\hline \multirow{2}{*}{ Husband's activity } & Employed & 0.413 & 0.253 & 1.511 & 0.102 \\
\hline & Unemployed (ref) & & & & \\
\hline Economic insecurity & & 0.045 & 0.050 & 1.046 & 0.365 \\
\hline Social insecurity & & -0.199 & 0.085 & .820 & $0.020 *$ \\
\hline Psychological insecurity & & 0.001 & 0.061 & 1.001 & 0.983 \\
\hline
\end{tabular}

Abbreviations: $\mathrm{HR}$, hazard ratio; SE, standard error.

* Significant at 0.05 level, ** Significant at 0.01 level.

studies considered the effect of both "demographic and socio-economic" and "insecurity" factors on birth interval simultaneously. Therefore, the aim of this article was to study influential factors including both "demographic and socio-economic" and "insecurity" factors on 610 Iranian women's first birth interval based on KM estimates and Log-Rank test for univariate and Cox $\mathrm{PH}$ model for multivariate survival analysis. According to the results, $\mathrm{KM}$ estimator of the first birth interval was $3.18 \pm 0.101$ years and almost $87 \%$ of women have given birth to their first child almost 5 years after their marriage. Although based on Log-Rank test, women's and their husband's educational levels and activities had significant effects on their first birth interval $(P<0.05)$, by considering simultaneous effects of all covariates, only women's educational level and social insecurity had significant effect on the first birth interval $(P<0.05)$.

Education, in addition to having long years of university life, can influence women's views on marriage. Providing access to alternative roles seems to be one of the issues where women with university education concentrate on instead of childbearing. Education can increase the possibility of identifying, inclining and taking on other roles and being involved in a range of social activities, the arts, sports, and technical skills and activities (22). Based on previous studies all over the world and especially in Iran, it was expected that by increasing women's educational level, the first birth interval also increased. In 38 out of 51 countries studying DHS data, illiterate women were more likely to have shorter birth intervals than educated ones (23). The survey conducted in seven countries in Asia also indicated that there was a negative relationship between education and the first birth interval (24). In the study conducted in Hamadan province, women's education was the only variable that had a significant effect on first birth interval (25). This result was also found in a study conducted by Shayan et al (26). This was in line with the results of this study in which hazard ratio of early childbearing in women with educational levels of secondary and high school and diploma were almost 2 and 1.6 times higher compared to those with MS and $\mathrm{PhD}$ degrees, respectively $(6,22)$.

The results of this study indicated that there was a strong negative relationship between women's social insecurity and their first birth interval. These results were consistent with some other studies (27-29). The most striking result emerged from the comparison of the data was that among several dimensions of insecurity including social, psychological and economic, only social insecurity was found to increase the first birth interval. The evidence of longer first birth interval can be clearly seen in the case of insecurity. In such situation, families define childbearing as a risk and then they will try to avoid any risk of childbearing. There are similarities between our findings and the attitudes expressed by Giddens and Beck regarding insecurity and new social risks, and the current study (30-32). A possible explanation for these results may be the lack of adequate welfare policies supporting women in Iran. Due to obstacles in balancing work and family life, low-paying jobs and also gender equality, social risks are more related to women in the family. Bonoli described this phenomenon as a type of new social risk (33). Some studies found that inadequate social security has a significant negative effect on fertility $(28,34)$.

Theoretically, the age of marriage is inversely related to the interval between marriage and the first birth, and those who are married at an early age are more likely to deliver their first child sooner (35-37). According to a study by Abbasi-Shavazi et al in Iran, women are not reluctant 
to delay marriage in the society because of the fact that they encourage early marriage and increase the level of education, but after marriage they use contraceptives and delay motherhood to achieve their goals. In this article, women's age at marriage did not have any significant effect on their first birth interval. It may be due to the fact that most women in the sample were married at 20 to 29 years of age. In addition, considering that women who were married at these ages were mostly those studied at higher educational levels, it does not appear to be affected by the impact of education level (3). Lack of influence of the age variable at the time of first childbearing in the presence of other covariates in the multivariate analysis confirmed the prominent role of education in this study.

\section{Conclusions}

Regarding the fact that the delay in childbearing is one of the main factors in fertility reduction, in order to prevent a further increase in the interval between marriage and the first birth, policymakers and governors should try to provide secure conditions for the families in which women reduce the interval between their age at marriage and childbearing.

A key policy priority should, therefore, be planned for the enhancement of social security among women. Based on the findings, unless governments provide the condition of social security, reducing the interval between age at marriage and childbearing will not be attained. Taken together, these findings do not support policies which are not in line with women's conditions but suggest an encouraging policy for educated women.

\section{Conflict of Interests}

Authors declare that they have no conflict of interests.

\section{Ethical Issues}

Not applicable.

\section{Financial Support}

This study was supported by National Population Studies and Comprehensive Management Institute, Tehran, Iran.

\section{Acknowledgements}

This article was extrapolated from surveys titled "Demographic Event Study by Parametric and SemiParametric Survival Analysis" and "Effects of Socioeconomic Rationality Dimensions on Childbearing Behavior in Tehran" supported by National Population Studies and Comprehensive Management Institute, Tehran, Iran in 2015 and 2016, with the registered numbers of 20/18627 and 21/26845.

\section{References}

1. Yohannes S, Wondafrash M, Abera M, Girma E. Duration and determinants of birth interval among women of child bearing age in Southern Ethiopia. BMC Pregnancy and
Childbirth. 2011;11(1):38. doi:10.1186/1471-2393-11-38

2. Kamal A, Pervaiz MK. Determinants of higher order birth intervals in Pakistan. J Stat.2012;19(1):54-82.

3. Abbasi-Shavazi MJ, McDonald P, Hosseini-Chavoshi M. The Fertility Transition in Iran: Revolution and Reproduction. Springer; 2009:75.

4. Abbasi Shavazi M, Razeghi Nasrabad H. Patterns and Factors affecting between marriage and first birth in Iran. Demography Society. 2010;5:75-105.

5. Erfani A. Tehran survey of fertility, 2009. Population Studies and Research Center in Asia and the Pacific. Tehran, Iran: Ministry of Science, Research, and Technology; 2010.

6. Abbasi-Shavazi M, Razeghi-Nasrabad HB. Patterns and factors affecting marriage to first birth interval in Iran. Journal of Population Association of Iran. 2012;5:75-107.

7. Central Statistical Agency, ORC Macro. Ethiopia Demographic and Health Survey, 2005. Addis Ababa, Ethiopia: Central Statistical Agency and ORC Macro; 2006.

8. Singh OP, Singh VK, Pathak DS. A Probability distribution for first birth interval. Can Stud Popul. 2006;33(1):69-81. doi:10.25336/P6MW42

9. McDonald P, Hosseini-Chavoshi M, Abbasi-Shavazi MJ, Rashidian A. An assessment of recent Iranian fertility trends using parity progression ratios. Demogr Res. 2015;32(58):1581-1602. doi:10.4054/DemRes.2015.32.58

10. Saadati M, Bagheri A. ideal first birth interval: a study of pre-marriage youths. Payesh 2017;16(2):239-250.

11. Torabi F, Abbasi-Shavazi MJ. Women's education, time use and marriage in Iran. Asian Popul Stud. 2016;12(3):229250. doi:10.1080/17441730.2016.1176806

12. Taniguchi H, Rosenfeld RA. Women's employment exit and reentry: differences among whites, blacks, and Hispanics. Soc Sci Res. 2002;31(3):432-471. doi:10.1016/S0049089X(02)00009-1

13. Uunk W, Kalmijn M, Muffels R. The Impact of Young Children on Women's Labour Supply:A Reassessment of Institutional Effects in Europe. Acta Sociol. 2005;48(1):4162. doi:10.1177/0001699305050986

14. Kreyenfeld M. Economic uncertainty and fertility postponement. Evidence from German panel data. Presentation Prepared for the Meeting of the Verein für Socialpolitik; 2005.

15. Kreyenfeld M. Uncertainties in Female Employment Careers and the Postponement of Parenthood in Germany. Eur Sociol Rev. 2010;26(3):351-366. doi:10.1093/esr/jcp026

16. Modena F, Rondinelli C, Sabatini F. Economic Insecurity and Fertility Intentions: The Case of Italy. Rev Income Wealth. 2014;60(S1):S233-255. doi:10.1111/roiw.12044

17. Abdolahi A. Effects of socio-economic rationality dimensions on childbearing behavior in Tehran. Tehran, Iran: National Population Studies \& Comprehensive Management; 2017.

18. Bagheri A, Saadati M. Desired childless survival interval analysis of pre-marriage youths: log-normal parametric model. Pajoohandeh. 2016;21(4):199-209.

19. Choe MK, Thapa S, Mishra V. Early marriage and early motherhood in Nepal. J Biosoc Sci. 2005;37(2):143-162.

20. Arnaldo C. Ethnicity and marriage patterns in Mozambique. Afr Pop stud. 2004;19(1):143-164.

21. Gyimah SO-M. The dynamics of spacing and timing of 
births in Ghana. PSC Discussion Papers Series. 2002;16(4): Article 1.

22. Saadati M, Bagheri A, Razeghi H. First Birth Interval and its determinants in Semnan Province by Parametric Survival Model. Journal of Population Association of Iran. 2015;10(19):63-87.

23. Setty-Venugopal V, Upadhyay UD. Birth spacing: three to five saves lives. Population Reports Series L: Issues in World Health 2002: 1-23.

24. MacQuarrie K. Trends and Factors Associated with Marriage Timing andthe First Birth Interval. Chicago: Population Association of America annual meetings; 2017.

25. Najafi-Vosough R, Soltanian AR, Fayyazi N. Influence Factors on Birth Spacing and Childbearing Rates using Survival Recurrent Events Model and Parity Progression Ratios. J Res Health Sci. 2017;17(3):e00384.

26. Shayan Z, Ayatollahi SM, Zare N, Moradi F. Prognostic factors of first birth interval using the parametric survival models. Iran J Reprod Med. 2014;12(2):125-130.

27. Salehi-Isfahani D. Iranian Youth in Times of Economic Crisis. Iran Stud. 2011;44(6):789-806. doi:10.1080/002108 62.2011.570510

28. Ehrlich I, Kim J. Social security and demographic trends: Theory and evidence from the international experience. Rev Econ Dyn. 2007;10(1):55-77. doi:10.1016/j.red.2006.09.002

29. Ejrnaes A, Boje TP. New Social Risks and Work-Family
Balance. In: Moreno Minguez A, ed. Family Well-Being: European Perspectives. Dordrecht: Springer Netherlands; 2013:131-149.

30. Giddens A. The consequences of modernity. John Wiley \& Sons; 2013.

31. Beck U. Risk society: Towards a new modernity. SAGE; 1992.

32. Beck U. World at risk. Polity Press; 2009.

33. Bonoli G. The politics of the new social policies: providing coverage against new social risks in mature welfare states. Policy Polit. 2005;33(3):431-449. doi:10.1332/0305573054325765

34. Boldrin M, De Nardi M, Jones LE. Fertility and social security. J Demogr Economics. 2015;81(3):261-299. doi:10.1017/dem.2014.14

35. Nomaguchi KM, Milkie MA. Costs and rewards of children: The effects of becoming a parent on adults' lives. Journal of Marriage and Family. 2003;65(2):356-74.

36. Mensch BS, Ibrahim BL, Lee SM, El-Gibaly O. Gender-role Attitudes among Egyptian Adolescents. Stud Fam Plann. 2003;34(1):8-18. doi:10.1111/j.1728-4465.2003.00008.x

37. Mohammadi Farrokhran E, Mahmoodi M, Mohammad K, Rahimi A, Majlesi F, Parsaeian M. Study of Factors Affecting First Birth Interval Using Modified Gompertz Cure Model in West Azarbaijan Province, Iran. Iran J Epidemiol. 2013;9(1):41-51.

(c) 2018 The Author (s); This is an open-access article distributed under the terms of the Creative Commons Attribution License (http://creativecommons.org/licenses/by/4.0), which permits unrestricted use, distribution, and reproduction in any medium, provided the original work is properly cited. 